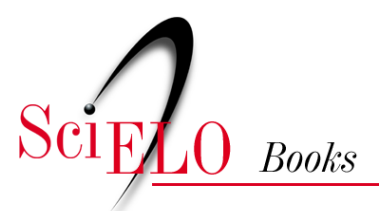

\title{
2 - Tecnologia e o Mundo da Vida
}

\author{
Don Ihde \\ Maurício Fernando Bozatski (transl.)
}

BOZATSKI, M.F., transl. IHDE, D. Tecnologia e o Mundo da Vida. In: Tecnologia e o mundo da vida: do jardim à terra [online]. Chapecó: Editora UFFS, 2017, pp. 42-54. ISBN: 978-85-64905-61-0. https://doi.org/10.7476/9788564905610.0005.

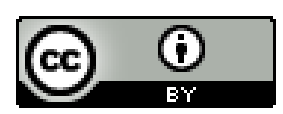

All the contents of this work, except where otherwise noted, is licensed under a Creative Commons Attribution 4.0 International license.

Todo o conteúdo deste trabalho, exceto quando houver ressalva, é publicado sob a licença Creative Commons Atribição 4.0.

Todo el contenido de esta obra, excepto donde se indique lo contrario, está bajo licencia de la licencia $\underline{\text { Creative Commons }}$ $\underline{\text { Reconocimento 4.0. }}$. 


\section{2 \\ Tecnologia e o Mundo da Vida}

A noção de tecnologia que eu desenvolvi até este ponto é a mais ampla possível enquanto ainda mantém uma ênfase sobre sua materialidade. Na metáfora inicial da navegação, tudo o que se pode distinguir é terra e mar. Agora é tempo para indicar mais precisamente quais métodos de navegação serão utilizados para se concluir a travessia.

O termo "mundo da vida" (lifeworld) será reconhecido pelos iniciados em filosofia como sendo o mesmo usado por Edmund Husserl em A crise das ciências europeias e a fenomenologia transcendental (1936). Enquanto eu não devo emprestar este termo e seu significado sem profundas modificações, ele servirá para localizar a investigação dentre as tradições da fenomenologia e de sua correlata origem hermenêutica. Essas tradições, no entanto, não são simplesmente idênticas. Fenomenologia, num sentido inicial e grosso modo, pode ser caracterizada como sendo o estilo filosófico que enfatiza certa interpretação da experiência humana e esta, em particular, concerne à percepção e a uma atividade corporal. Hermenêutica, por outro lado, surgiu a partir das disciplinas da interpretação textual e, posteriormente, um tipo de análise linguística (Continental). Se Husserl permanece como a figura central na fenomenologia, seu jovem colega, Martin Heidegger, foi o desenvolvedor central da hermenêutica fenomenologicamente orientada, ainda que ele também possa ser considerado o fundador da filosofia da tecnologia contemporânea. As conexões entre estas linhas filosóficas não são imediatamente aparentes. A investigação aqui une estas linhas em 
uma única que se propõe de maneira descritiva analisar tecnologia e o mundo da vida. Começando com a fenomenologia das relações humano-tecnologia e então se movendo para a hermenêutica do enraizamento tecnológico-cultural, o primeiro programa é este, e mesmo que desenhado a partir das tradições mencionadas, não se limita às suas formas passadas.

Existe certo risco em abertamente começar com a fenomenologia das relações humano-tecnologia porque, em seu foco experimentalista, a fenomenologia tem sido amplamente mal compreendida como sendo a análise puramente "subjetiva". Mesmo que na recente filosofia norte-americana da ciência tenha aparecido alguns esclarecimentos sobre tais compreensões distorcidas, certo pré-juízo ainda permanece junto às tradições dominantes.

Se for verdade que a filosofia fenomenológica tornou-se a análise da experiência humana, seu entendimento da ideia de vivência não é o mesmo que o entendimento do senso comum nem o das interpretações equivocadas dos padrões da fenomenologia como sendo subjetiva. Eu proponho compreender este problema diretamente por meio da delimitação de vários aspectos da vivência e o seu entendimento fenomenológico.

Na psicologia - disciplina que se poderia pensar intuitivamente ser a mais adequada para questionar a "vivência" - seus termos estão obsoletos. Vivência tornou-se como sendo, redundantemente, experiência subjetiva, e a maneira de acessá-la é por meio da introspecção. O conceito behavior (comportamento) substitui o que vinha sendo experiência; behavior era tido como aquilo que era externo e observável. Recentemente a versão de mundo vivido, na qual uma de suas dimensões é a não externamente observável interioridade, tem voltado nas psicologias conceituais. Mas em outro sentido, a vivência nunca de fato deixou a prática da psicologia. Ela está implícita na própria situação experimental.

Na prática, o psicólogo elabora uma experiência na qual o "sujeito" participa de alguns testes, tarefas ou o que seja. O psicólogo que também é um sujeito em certo sentido observa o experimento, interpreta seus resultados, etc. Mas qual é o status da observação? Ela não é experiência no estrito sentido? Agora, admitidamente, psicologia não é uma disciplina autorreflexiva, e nem o são a maioria das ciências em um sentido temático. Assim, a observação em si de uma experiência é tida funcionalmente como certa, embora existam controles dentre a comunidade de psicologistas para o criticismo de um procedimento experimental e implicitamente para a observação-vivência. Mas é obvio que sem a observação-vivência não pode haver ciência da psicologia. Nem se 
pode permitir a esta observação-vivência ser "meramente subjetiva", para que a psicologia em si não se torne um tipo de relativismo (para cada uma de suas próprias observações).

Uma análise fenomenológica preliminar da situação-vivência pode ajudar a clarificar a noção implícita de vivência de tais funções junto à psicologia. Fenomenólogos defendem que todas as vivências são experiências de alguma coisa. Isto é, vivência é referencial, e aquilo que é referido ou experimentado é alguma coisa que pode preencher o vazio. No caso dos psicólogos observando um experimento, o vazio pode ser:

\section{Psicólogo $\rightarrow$ (sujeito submetido a uma tarefa)}

Se o psicólogo não observa o experimento de fato, então podem ser simplesmente os resultados que serão vivenciados:

$$
\text { Psicólogo } \rightarrow \text { (resultados) }
$$

Em ambos os casos, o psicólogo vivencia o referencial, seja numa observação direta ou numa observação secundária (e o fenomenólogo pode muito bem apontar que a primeira é uma tarefa perceptual informada, e a segunda é um exercício mais explicitamente hermenêutico-perceptual).

A vivência do psicólogo é necessariamente "subjetiva" em certo sentido, mas também é mais que subjetiva, pois possui seu próprio contexto de limitação ou "objetividade". Tais limitações incluem revisão por pares (intersubjetividade), delineamento experimental (restrições de contexto) e assim por diante. O treinado, observação de especialistas, é simplesmente um tipo particular de vivência, mas que certamente não é simplesmente "meramente subjetivo." E a mesma estrutura da vivência de 1 pertence para cada uma das ciências.

Se a psicologia, por suas próprias razões peculiares, decidir reduzir seu objeto de estudo às suas "externas" ou diretamente observáveis dimensões, a física tem sido mais sofisticada no que diz respeito à dificuldade em isolar o objeto. Por exemplo, o "comportamento" dos átomos e seus constituintes não são diretamente observáveis, mas são disponibilizados por meio da mediação tecnológica (instrumental) nas situações de observação. A câmara de bolhas, os aceleradores e os microscópios eletrônicos e computadorizados, todos trazem a mediada ou a presença indireta do microfenômeno, que é de interesse para o

1 Lacuna presente no texto original, o que também ocorre em outras partes. 
físico. Mas o físico, tal como o psicólogo, pode insistir que a experiência envolvida na observação deve ser de um tipo especial. Ela deve ser uma observação treinada e informada, e o observador deve passar por um aprendizado adequado, ainda que todas as experiências permaneçam experimentais, sem o que não poderia haver ciência. A filosofia, e em particular a fenomenologia, toma, no entanto, como seu primeiro fenômeno a estrutura da experiência em si mesma. Mas se a estrutura da experiência tornou-se o tema dominante da fenomenologia, isso ocorreu apenas porque o alcance completo e as múltiplas dimensões de tal estrutura precisam ser examinados. Por essa razão, Husserl inicialmente caracterizou seus passos iniciais como sendo a "ciência das vivências". Tal ciência não pode simplesmente reduzir seus campos a algum aspecto arbitrário do todo. Ambos os aspectos - externos e internos, subjetivo e objetivo - devem ser incluídos. Nesse sentido, a fenomenologia retém uma estratégia não redutivista no que diz respeito ao seu campo de investigação.

Num sentido mais profundo, no entanto, a fenomenologia, no que diz respeito à experiência, não se limita a um paralelismo com a psicologia. Antes disso, ela vai além ao produzir reivindicações ontológicas muito mais fortes. Isto é demonstrado no desenvolvimento subsequente da fenomenologia produzido por Martin Heidegger em Ser e Tempo (1927). O fato de tornar existencialista a ciência do mundo vivido de Husserl foi, de fato, o desenvolvimento do que eu denominarei de ontologia relativista da existência humana. Aqui eu devo apontar que um perfil relativista não é necessariamente um relativismo. Antes, um perfil relativista é um perfil das relações. No caso de Heidegger, trata-se de um perfil das relações humano-mundo, as quais determinam e definem as dimensões da existência humana (Dasein). Ser e Tempo tinha um perfil da espacialidade humana junto ao Mundo, da temporalidade humana junto ao Mundo e das várias estruturas e dimensões das relações humano-mundo.

De fato, eu sugiro como modelo metafórico para entender a fenomenologia precisamente o da ciência relativista. Uma maneira simples de afirmar este modelo é indicar que o primitivo do sistema (a menor ou mais simples unidade) é em si um conjunto de relações:

$$
\text { Eu---relação---Mundo }
$$

E ao passo que eu deva fazer tais relações mais precisas quando o programa a respeito das relações humano-tecnologia iniciarem, eis aqui uma comparação preliminar junto a um exemplo de relativismo bem famoso que pode ser 
utilizado. Trata-se de uma modificação sobre o exemplo de Einstein empregado para ilustrar as observações relativistas.

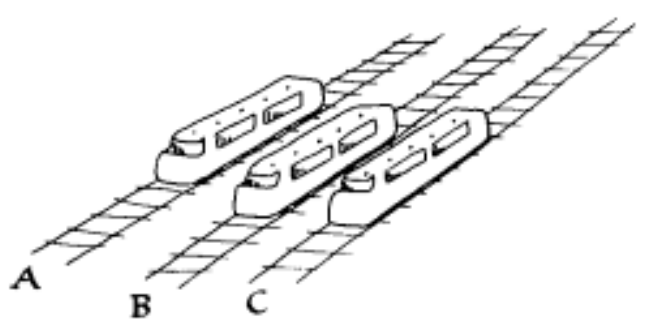

Se existirem três trens em três trilhos paralelos, o movimento observado vai ser relativo: (a) à posição do observador em relação; (b) ao que é observado. Relativo, neste caso, é que aquilo que se observa e a posição de onde se observa e a inter-relação entre ambos também deve ser levada em conta. Assim, se o observador estiver parado no trem $\mathrm{B}$ e notar que o trem $\mathrm{C}$ está se movendo para trás, algumas hipóteses são possíveis: ou o trem $\mathrm{B}$ está parado e o trem $\mathrm{C}$ está se movimentando para trás; ou o trem C está parado e o trem B está se movimentando para frente, fazendo parecer para alguém no trem $B$ que o trem $C$ está voltando para trás; ou que ambos os trens estão em movimento. Colocar observadores nos trens A e C e considerar todas as possibilidades de movimento dos trens pode demonstrar toda a complexidade desta situação, mas em cada caso existe uma "estabilidade" na relação observador-observado.

Também pode notar-se que em tal situação relativista, que toma em consideração igualmente observador-observado (como uma relação), pode também absorver conceitualmente qualquer situação absoluta ou não observacional. Por exemplo, quando ingenuamente perguntamos qual trem está "realmente" se movendo, nós podemos elaborar uma quarta posição de observação: uma torre de observação, D, a qual permite uma visão panorâmica de todo o espaço (Figura 2). Um observador aqui pode não estar sujeito à relatividade dos observadores dentro dos trens e pode dizer qual das hipóteses era "verdade". 


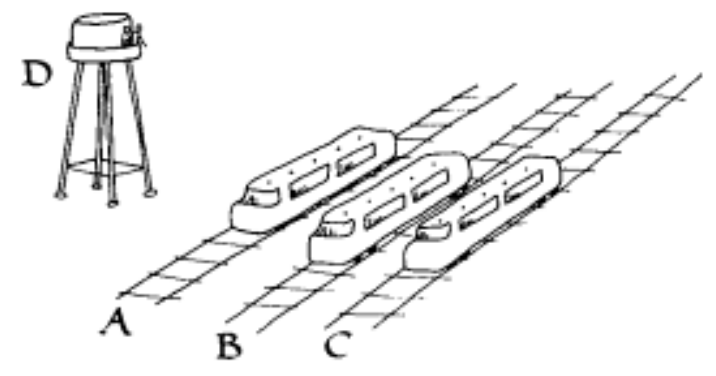

Esta posição privilegiada não escapa do poder absortivo do fato relativístico; no entanto, tomar tal posição como sendo privilegiada é simplesmente separar a relatividade entre o observador e o que é observado. Isso faz o espectro daquilo que é descrito mais compreensivo e mais complexo. A situação agora consiste em trens tal como descrito (em movimento ou não) em relação ao solo (que é tido como algo que não está se movendo), mas isso não elimina a relatividade da situação de forma alguma. A "arbitrariedade" regional de empregar superioridade à posição da torre pode em si ser transcendida para uma situação em que a terra em si é observada a partir de algum ponto mais distante, o que pode demonstrar que o que foi tomado como sendo imóvel, tal como o solo em si, é relativo ao movimento de toda a terra ao longo de sua órbita, e assim ad infinitum. Porém, a constante do observador-observado deve permanecer a mesma não importando qual seja a distância ou posição ocupada.

A perspectiva fenomenológica, tal como a relativista esboçada, sempre toma como primitivo a relatividade do humano no campo da experiência. Nesse sentido, ela é rigorosamente relativista. A relatividade das relações humano-mundo são reivindicadas por fenomenólogos como sendo um aspecto ontológico de todo o conhecimento, de toda a experiência. Negativamente, poderia ser reivindicado que não existe nenhuma forma de "escapar" desta situação relativista, e qualquer reivindicação contrária pode ser apontada como sendo igualmente ingênua ou equivocada. Nesse sentido, a fenomenologia é para todas as filosofias fundacionistas o que a relatividade é para a física newtoniana.

Esses são comentários gerais sobre o modelo fenomenológico de conhecimento e experiência. Para nos aproximarmos da investigação mais específica sobre as relações humano-tecnologia, uma segunda ciência análoga pode ser utilizada. A qualquer coisa mais que possa se juntar à análise das relações humano-tecnologia, pretendo manter o senso de materialidade que são próprios 
das tecnologias. Tal materialidade é correlata à nossa materialidade corpórea, a experiência que temos como sendo com nossos corpos em um ambiente. A ciência análoga aqui poderia ser a ecologia animal.

A ecologia é igualmente relativista, mas num sentido mais concreto e biológico. Ela é o estudo dos organismos em relação aos seus ambientes, no interior de alguns sistemas ecológicos específicos. Falando de maneira breve, um organismo é estudado em relação ao seu campo, seja simples ou complexo. Aqui, novamente, é algo análogo ao modelo da figura do solo. A figura (organismo) inter-relaciona-se com seu solo (meio-ambiente), e o estudo desta interação é a ecologia. Fenomenologia, particularmente no que diz respeito à sua atividade de tornar existencialista a existência corpórea, é um tipo de ecologia filosófica. Mas se trata de uma ecologia com uma diferença: O "organismo" que deve ser estudado não é e não pode ser estudado "a partir do exterior" ou de sobrevoo, porque, neste caso, nós somos ele. A ecologia humana que é fenomenologia é assim, duplamente, existencialista e relativista.

No exemplo einsteiniano, posições imaginárias podem ser assumidas arbitrariamente. Num sentido mais fundamental, no entanto, há sempre uma posição em que um ser finito e corpóreo precisa assumir e de fato ser. De maneira similar, ecologicamente, pode existir uma ampla variedade de estruturas organismo-ambiente, embora existam condições complexas relacionadas a cada uma, as quais devem ser ocupadas. E tal estrutura necessariamente possui seus correlatos corpóreos.

Ao utilizar as analogias destas duas ciências relativistas, pode-se notar que filosofia fenomenológica, mesmo que não eliminando a interioridade ou o aspecto "privado" da experiência humana, em nenhum sentido é limitada a eles. Ao contrário, seus limites são aqueles impostos pelo contexto relativista das relações (eu-mundo) e ulteriormente contrastados pelo reconhecimento explícito que, neste caso, um polo da relação é o que eu sou (junto à relação).

É também junto a esta conjectura que a apropriação possível da relatividade fenomenológica faz contato com a descrição das relações humano-tecnologia. Eu tenho insistido repetidamente que a materialidade das tecnologias se dão na concretude como numa espécie de "hardware" que num sentido mais amplo se conecta com a nossa existência corpórea igualmente concreta. Em sua história, a fenomenologia teve um crescente desenvolvimento existencial, e o termo "existencial" neste contexto se refere à experiência corpórea e ao sensível, uma forma de "materialidade fenomenológica". Tecnologias, nesse sentido, não são 
apenas apropriadas para a análise; elas recaem quase que naturalmente para o centro do debate filosófico.

Tecnologias, ao passo que elas são artefatos (num espectro que vai de simples entidades a todo um conjunto de sistemas complexos), são desenvolvidas, usadas e relacionadas aos humanos de formas distintas. Enquanto ainda existe certa necessidade em classificar as tecnologias como objetos (que é frequentemente o primeiro foco das descrições objetivistas), o que será levado em conta aqui são os conjuntos de relações humano-tecnologia, as relações que podem ser melhor exemplificadas numa forma sugerida de descrição relativista.

Existem algumas vantagens táticas para tal abordagem. Primeiramente, a relatividade fenomenológica evitará o que é considerado como sendo dois resultados extremistas em muito da literatura sobre o tema. Uma posição extrema é a que ultimamente reifica as tecnologias em Tecnologia. Uma versão de tal movimento, já mencionada, é a que absorve a tecnologia na técnica. Técnica, por sua vez, torna-se uma forma de prática e pensamento, que é tão geral que não é capaz de diferenciar entre as relações particulares humano-tecnologia e a sua inclinação para demandas excessivamente metafísicas.

No uso que eu faço pode haver técnicas com ou sem tecnologias. Uma "técnica” sexual não é em si uma tecnologia (embora, num sentido derivado e secundário, se tal técnica é modelada a partir de algum processo mecânico, então haverá uma conexão interpretativa entre as duas). Igualmente, técnicas podem estar intimamente ligadas às tecnologias, particularmente no que diz respeito aos padrões de uso.

A segunda vantagem de uma descrição relativista é a de superar o estado de coisas que argumenta sobre a presumida neutralidade das tecnologias. Interpretações neutralistas são invariavelmente não relativistas. Elas sustentam, com efeito, que as tecnologias são coisas em si, objetos isolados. Tal interpretação se localiza ao extremo oposto da posição de reificação. Tecnologias em si mesmas são concebidas como simples objetos, como tantos outros pedaços de lixo que estão à nossa volta. A arma no adesivo do vidro traseiro claramente, por si mesma, não faz nada; mas numa perspectiva relativista em que a unidade primitiva é a relação humano-tecnologia, torna-se imediatamente óbvio que a relação humano-arma (um humano com uma arma) frente a outro objeto ou outro humano é bem diferente de um humano com uma arma. A relação humano-arma transforma a situação de qualquer situação similar de um humano sem uma 
arma. Ao nível das megatecnologias, pode-se notar que os efeitos transformadores serão similarmente ampliados.

A terceira vantagem tática é a de preservar junto à análise algo do senso dinâmico ou ativo que se obtém nas relações humano-tecnologias. Não apenas as tecnologias são artefatos, mas elas são usadas (bem como são desenvolvidas, descartadas, etc.) em sua função normativa. E, embora o uso possa ser imediato, distante, ocasional ou postergado, a relação humano-tecnologia implica uma práxis humana ou ação. Como uma filosofia, a fenomenologia em si pertence à família das filosofias da práxis surgindo a partir de Hegel, Marx, pragmatismo e, num sentido derivado, do existencialismo. Humanos são o que são em termos da relação humano-mundo, mas essa relação na existência é acional. Igualmente os envolvimentos corpóreos-perceptivos e o desenvolvimento da noção de práxis serão essenciais para a investigação.

Há outra dimensão da fenomenologia que precisa ser mencionada nesta descrição preliminar. Não se trata apenas de um perfil relativista nos aspectos descritos, mas também estrutural. No exame de qualquer gama de relações que o fenomenólogo se comprometa, o que se busca é uma descrição, uma compreensão das estruturas de tais relações. Este será o objetivo mesmo: que as estruturas se mostrem simples e unidimensionais ou complexas e multidimensionais. Tal exame deve revelar igualmente os aspectos variáveis e invariáveis de tais estruturas. As questões aqui serão: quais estruturas relacionais se obtém no que diz respeito às relações humano-tecnologia? Quais são estes elementos diferentes de uma descrição fenomenológica que serão sintetizados? Qual é a dinâmica da atividade corpórea-perceptiva na práxis ativa a ser combinada com a elucidação de tais estruturas relacionais? Essa é a função da noção de mundo da vida. Sua origem, historicamente, vem de Husserl nos últimos dias de sua carreira, mas também pode ter sido a sua resposta ao apontamento inicial e mais histórico e existencial das relações humano-mundo feito por Heidegger. Em qualquer caso, no desenvolvimento husserliano da ideia de mundo da vida, repousam indícios que combinam os elementos necessários para unificar o tema desta investigação.

Superficialmente pode parecer que o objetivo de Husserl em seu contexto próprio é contrário ao foco necessário aqui. A crise nas ciências europeias e a filosofia contra a qual Husserl estava argumentando, em parte, era a mesma que depois teve que se opor ao Positivismo, uma ameaça à ideia do progresso científico racional. Em sua própria resposta, Husserl buscou desenvolver uma teoria do progresso racional isolando os meios em que ciências eidéticas - nas 
quais a matemática e a geometria eram os exemplos primordiais - poderiam surgir a partir de um contexto prévio mais concreto e material. Então, tais ciências eidéticas poderiam ser idealizadas ou tornadas autônomas das condições materiais e, assim, de maneira cuidadosa e qualificada, ser consideradas então como acumulações culturais. Sua análise repousava sobre o desenvolvimento dos graus crescentes do ideal ou abstração.

A respeito disso, há um sugestivo núcleo contendo sua derivação e conceito sobre o mundo da vida que pode ser redirecionado para a investigação acerca da tecnologia. Depois eu devo argumentar mais sobre derivação, mas inicialmente a ilustração que ele fornece no famoso apêndice à Crise, "A Origem da Geometria”, pode abrir o caminho para os aspectos chave da noção de mundo da vida:

É evidente que, na vida das necessidades práticas, certas particularizações de forma se destacaram e que uma práxis técnica sempre voltada para a produção de formas particulares preferidas e para a melhoria delas de acordo com certas direções de gradualidade. O primeiro a ser destacado a partir da coisa-forma são superfícies mais ou menos "lisas", mais ou menos perfeitas superfícies; contornos mais ou menos ásperos, ou bastante "planos"; em outras palavras, linhas mais ou menos puras, ângulos, pontos mais ou menos perfeitos; então, novamente, dentre as linhas, por exemplo, linhas retas são especialmente preferidas; e dentre as superfícies, as superfícies planas, para propósitos práticos, por exemplo, bordas limitadas por superfícies planas, linhas retas e pontos são os preferidos, enquanto superfícies totalmente curvadas são as indesejadas para muitos dos interesses práticos. Assim, a produção de superfícies planas e sua perfeição (polimento) sempre desempenha seu papel na práxis. ${ }^{2}$

Husserl está justamente interessado na origem do pensamento geométrico a partir das atividades práticas. Mundo da vida combina igualmente um perfil genético (histórico) e um estrutural. $\mathrm{E}$ a derivação claramente demonstra, apesar do racionalismo de Husserl, a proximidade com as filosofias da práxis (tais como as de Marx e Dewey) na medida em que algumas espécies de ações subjazem posteriormente em desenvolvimentos mais abstratos.

No exemplo empregado, o qual eu devo chamar de o "exemplo mobiliário", Husserl trai sua escolha usual de coisas familiares bem como a sua estrutura metafísica implícita. Ao nível da atividade prática, coisas são coisas materiais

2 HUSSERL, Edmund. The Crisis in European Sciences and Transcendental Phenomenology; trans, David Carr. Evanston: Northwestern University Press, 1970, p. 375. 
e basicamente vivenciadas em plena (multidimensionais e complexas), e aqui elas são colocadas em prática por um marceneiro. $\mathrm{O}$ emergente geômetra à espreita no marceneiro começa a nascer, selecionando e preferindo alguns aspectos de seu material (bordas, tal como Husserl sugere). Aqui devemos notar que Husserl é crítico e suficientemente ciente de que tal seleção é, de fato, uma escolha e implica que outras trajetórias possam ser tomadas. A escolha do geômetra, no entanto, origina-se na preferência por um conjunto de formas (pontos, linhas retas, superfícies). E ao se concentrar e desenvolver sobre elas, uma nova (e não marceneiro) prática pode ser desenvolvida. (O exemplo de Husserl sempre me pareceu "cozinhado". Fosse o marceneiro construir um navio, por exemplo, suas escolhas de forma seriam muito diferentes; elas incluiriam uma preferência por curvas, curvas compostas, cônicas, em vez de ângulos simples, superfícies e linhas no exemplo de Husserl. Mas esta escolha teria feito a conexão com a origem da geometria mais difícil, de fato, uma vez que, em contraste com a geometria plana, a geometria mais complexa necessária no exemplo para a construção de navios dificilmente poderia ser a geometria primitiva. Historicamente, é claro, a construção naval continuou sem uma ciência geométrica até recentemente na história.)

A práxis geométrica, uma vez derivada e tornando-se autônoma, carrega consigo um novo conjunto de formas de visão. Ela é uma aquisição cultural que pode ser repetida e, assim, uma vez sedimentada na experiência cultural, se torna intuitiva ou tomada como certa. (Aqui outro mal-entendido grotesco da fenomenologia pode ser mencionado. A acusação de que a fenomenologia recai no "mito daquilo que é dado", tal como Wilfred Sellars pode ter feito, é simplesmente falsa. Husserl frequentemente se referre ao que é intuitivamente dado, mas ele se valeu disso inicialmente; isto é, era para servir como um tópico para ser investigado. Contrariamente, intuições, tal como o exemplo do geômetra aponta, são constituídas. Apenas quando já constituídas e feitas familiares é que elas se tornam totalmente intuitivas ou "dadas".)

O problema que emergiu para Husserl foi aquele que agora é visto como sendo dois níveis de práxis: um material e prático (o contexto do marceneiro) e o outro ideal e teorético (o contexto do geômetra). Ambos pertencem, em certo sentido, ao mundo da vida, e ambos podem ser familiarizados com certo padrão praxiológico. Em parte, no entanto, esta tensão surge porque Husserl combinou dois tipos bem diferentes de práxis e fez com que um derivasse do outro. 
A modificação que devo fazer aqui sobre o exemplo e Husserl é no sentido de distinguir dois sentidos da percepção. O que é usualmente tomado como percepção sensorial (o que imediatamente e corporalmente focada na que se vê, se ouve, no momento atual), eu denominarei micropercepção. Mas também há o que pode ser chamado de percepção cultural, hermenêutica, o que denominarei macropercepção. Ambas pertencem igualmente ao mundo da vida. $\mathrm{E}$ ambas as dimensões da percepção estão intimamente conectadas e entrelaçadas. Não existe micropercepção (sensorial-corpórea) sem sua localização junto ao campo da macropercepção e não há macropercepção sem o seu foco microperceptivo.

A relação entre o a micro e a macropercepção não é uma derivação; ao contrário, ela é mais parecida com as figuras da Gestalt em que a micropercepção ocorre de acordo com um contexto hermenêutico-cultural; mas todos estes contextos realizam-se apenas no alcance das possibilidades microperceptivas. A implicação para a noção de mundo da vida será que esta investigação vai ser não fundacionista com algumas claras qualificações que precisam, assim, serem necessariamente colocadas sobre a ideia de acumulações.

Essa modificação sobre as distinções husserlianas tradicionais pode permitir uma descrição clarificante de como o mundo da vida se transforma. $\mathrm{Na}$ medida em que as macropercepções variam radicalmente, a relação para qualquer micropercepção também deve variar, ao menos no contexto do significado. Histórias culturais são histórias variantes, mas elas permanecem focadas na nossa existência corpórea.

Mais imediatamente, esta modificação implica uma análise em dupla face sobre o alcance das relações humano-tecnologia dentre os limites da micropercepção e experiência corpórea; o outro aspecto da análise deve permanecer sobre a hermenêutica cultural que situa nossa vida existencial. Na medida em que a percepção corpórea tem uma estrutura, vou alegar que sua estrutura multidimensional fornece certos contrastes sobre a perceptividade e que ela também possui uma série multiestável de ambiguidade, tal que essa estrutura é compatível com vasta série dos diferentes contextos cultural-hermenêuticos. Dessa forma, a análise deve ser completada tendo em conta o campo último em que tal micropercepção possa ocorrer.

Virtualmente, todo exemplo do intercâmbio entre o humano-tecnologia pode ilustrar esta inter-relação. Tome a seguinte interpretação sobre a estória da raposa e das uvas: a raposa, vendo que as uvas eram muito altas para serem alcançadas pela capacidade de salto de seu corpo, conclui que as uvas eram azedas; 
mas os humanos, inicialmente também incapazes de alcançar ou pular até as uvas, pegam uma vareta e derrubam as uvas, assim não acham ser necessário concluir que as uvas são azedas. Ambos, raposa e humano, no sentido microperceptivo mais estreito, percebem as uvas como sendo comestíveis e desejáveis, mas o contexto tecnológico primitivo tornado possível pela vareta muda o sentido perceptivo das uvas como atingíveis e, com ele, a macropercepção que o humano tem igualmente sobre o objeto da percepção e sobre sua habilidade de obter tal objeto. 